\title{
Public Private Partnership (PPP) in Health Sector of Bangladesh
}

\author{
TT Sajani ${ }^{1}, \mathrm{~K} \mathrm{Alo}^{2}$, SAQM Aktaruzzaman ${ }^{3}$ \\ ${ }^{1}$ Dr. Tabassum Tahmin Sajani, Assistant Professor, Department of community medicine, AKMMC, Dhaka \\ ${ }^{2}$ Dr. Kamrunnahar Alo, Interns Khwaja Yunus Ali Medical College Hospital, Enayetpur, Serajganj \\ ${ }^{3}$ Syed AQM Aktaruzzaman, M.phil Fellow, Bangladesh University of Professionals \\ *Corresponding author
}

\begin{abstract}
Public- Private Partnership (PPP) describes a government service or private business venture which is funded and operated through a partnership of government and one or more private sector companies. The term public refers to government including both central and local level state institutions. Defining private sector has become complicated due to the emergence of a large number of institutions called NGOs. The distinction of the private sector and NGOs is often blurred due to various sizes, functions and objectives of NGOs. The simplest way to distinguish between these two is: in case of profit private sector encompassing commercial enterprises of any size and for non-profit private including NGOs sector, which provides voluntary services. This review has grouped both the profit private sector, and non-profit NGOs under the term private sector. It also highlights PPP concept, importance, financing approaches as well as examples of model partnership in health sector in particular.
\end{abstract}

Key words: Parathyroid gland, histology, parenchyma, stroma

\section{Introduction}

PPP involves a contract between a public sector authority and a private party, in which the private party provides a public service or project and assumes substantial, technical and operational risk in the project. In some types of PPP, the cost of using the services is borne exclusively by the users of the services and not by the taxpayer. In other types (notably the private finance initiative), capital investment is by the private sector on the strength of a contract with government to provide agreed services and the cost of providing the service is borne wholly or in part by the government. In case where the government has invested in the project, it is typically (but not always) allotted an equity share in the "Special Purpose Vehicle" (SPV) ${ }^{1}$.

In 1992, the conservative government of John Major in the UK introduced the Private Finance Initiative (PFI), the first systematic program aimed at encouraging public-private partnerships $^{2}$. Over the past two decades more than 1400 PPP deals were signed in the European Union, which represent an estimated capital value of approximately $\$ 260$ billion.
Since the onset of the financial crisis in 2008, estimates suggest that the number of PPP deals closed has fallen more than 40 percent $^{3}$. These difficulties have placed significant strains on governments that have come to rely on PPP $s$ as an important means for the delivery of long-term infrastructure assets and related services ${ }^{4}$. Moreover, this has occurred precisely at a time when investments in public-sector infrastructure are seen as European Commission communication on PPPs ${ }^{5}$. As a result of the importance of PPP s to economic activity, in addition to the complexity of such transactions, the European PPP Expertise Centre (EPEC) was established to support publicsector capacity to implement PPP s and share timely solutions to problems common across Europe in PPPs ${ }^{6}$. The sectors of PPP in Bangladesh includes: Health sector, Education sector, Infrastructure development, Tourism sector, ICT sector and Industries. Public-Private Partnerships (PPP) in health sector services can be described as a long-term contract (typically 15-30 years) between a public-sector authority and one or more private sector companies 
operating as a legal entity. Funding sources could include banks, private equity firms, philanthropists and pension fund managers. As PPPs move from financing infrastructure to managing care delivery, there is an opportunity to reduce overall cost of healthcare.

In considering the concept of private health sector \& financing approach in Bangladesh, the private sector in health is generally understood to refer to private, for profit, medically trained providers. Their range of practice varies from solo practice, small nursing homes, to large hospitals. The private sector also offers ancillary services such as diagnostic centers, ambulance services, and pharmacies.

The objectives of health system activities by the private health is to promote, maintain

and to recover people's health. In the private health care system, three broad categories of actors e.g. "people", "The State", and "Private Sector Actors" are considered as major stakeholders. "People" are considered at the centre of this system. The "State" is represented by the Ministry of Health and Family Welfare, Directorate of Health, Directorate of Family Planning at the central, state and local levels, whose primary activities relate to the health sector. The functions of private health care system include financing, input management (non-financial), and health services delivery. Health status, financial protection and consumer responsiveness are three major types of outcomes in health sector. Health status is generally determined by several indicators e.g. mortality, fertility, nutrition, illness, disability etc.

Health financing approaches \& mechanism in private sector includes public financing, health insurance, user fees, and donor financing, nonstate collective non-profit-making financing and development loans. Allocation of financial resources is a major issue in a country with limited resources. The World Bank also calculates that total annual spending of eight dollars per person is more than enough to provide acceptable standards of clinical care ${ }^{7}$. According to the recent estimate by the WHO Commission on Macroeconomics and Health (2001) the set of essential interventions costs, on average, about \$34 per person per year, which is much higher that the current level of public spending of around $\$ 5$ recorded for

Bangladesh. The huge resource gap in financing the health needs of the poor cannot be met without additional resource mobilization from external resources ${ }^{8}$.

The sources of health financing in Bangladesh include government allocation, loan from World Bank and other financial institutions, International Development Agencies, financial assistance from NGOs, community participation in cost-sharing, health insurance system, health cooperative systems, private investment by business entrepreneurs, income-generating mechanisms, bank loan, joint ventures etc. The largest proportion of funding for healthcare comes from household expenditure 63\%, followed by $18 \%$ MOHFW Development Budget, 13\% MOHFW Revenue Budget, 3\% Non-Profit NGOs and Donors and 3\% Other Public Revenues 9 .

In Bangladesh, private sector health financing includes household expenditures, private nursing home investments and drug funds from nongovernmental organizations (NGOs). Most Bangladeshi usually obtain majority of their drugs from the private sector. Private nursing homes, doctors in private clinics and other health practitioners prescribe medicines to patients who must buy them at full price. Private expenditures for pharmaceuticals in developing countries typically account for 50 to $90 \%$ of all expenses of drugs. Even for the rural people and the urban poor, the most common source of drug is direct out-pocketing purchase from the private market ${ }^{10}$. According to National Health Accounts the largest single source of health care financing is direct payments by households, which accounts for $63 \%$ of the total. Government financing is only the second largest source of funds, contributing to $34 \%$ of the total, NGOs, private insurance and employer's together account for less than $1 \%$ of total financing ${ }^{10}$.

Several approaches of private sector health financing are in practice:

Private household expenditure: Households bear the major portion of the total health expenditure $(63 \%)$ in Bangladesh. User Charges: Faced with limited resources for health and population services. Health insurance system: Commercial 
health insurance is extremely limited in Bangladesh. During 1997-98, there was only one company providing health insurance 10 . There are two other prominent approaches for rural risk sharing systems in Bangladesh e.g. Gonosasthya Kendra Health System is Savar and Grameen Bank Prepaid Health plan ${ }^{11}$. Gonosasthya Kendra Health System, in Savar, covers 37,000 households. In this system the annual premium is Tk.3-10, medicines are free or reduced $25 \%-75 \%$, and consultation fee is Tk.3-5 for the poor. Grameen Bank prepaid health plan system covers 38,000 households. The annual premium is Tk.5,070 and consultation fee is Tk.2 for the poor. Community-based insurance scheme: Some NGOs are trying to establish community based insurance scheme especially in their catchments area, but their efforts are yet insignificant and pilot in nature. Private Firm Expenditure: The largest known example of employer provided health services is in the tea garden, where employers have traditionally provided on site medical services to their workers. The largest three tea companies spent Tk.80million on health care provided to their employees 12. Many entrepreneurs in the Export Processing Zone (EPZ) and few Ready Made Garment (RGM) realizing the potential linkages between workers good health and the productivity have introduced health services for their workers (78\% female workers) in the factories. It is in the embryonic stage, and the interventions have high potentials to grow in the future. Private investment by business entrepreneurs: A large number of entrepreneurs have already invested for establishing private hospitals, diagnostic clinics for profit. Private health initiative in association with local government institutions: Some of the municipalities offer health services utilizing their own resources. These efforts can be strengthened in association with local government institutions. Private nursing home and pathological laboratory investment: Hundreds of private nursing homes, hospitals and pathological laboratories have been operated in Bangladesh through private investment.

EPI \& Nutrition as model of partnership: Expanded Program of Immunization (EPI) is one of the greatest public health achievements of the government of Bangladesh. The Expanded Program of Immunization (EPI) including vaccination against six diseases: neonatal tetanus, polio, diphtheria, measles, tuberculosis and pertussis, was globally launched in 1974 and was formally launched in Bangladesh on April 07, 1979. The intensified immunization program was expanded in the country in phases and near universal coverage was achieved by the end of $1989^{13}$.

The government made a strong commitment to improving its national EPI program with the technical and financial assistance of international donors. The international partners of the program include the World Health Organization (WHO), UNICEF, USAID, The Japan International Corporation Agency (JICA), Rotary International, The Swedish International Development Agency and GAVI (Global Alliance for Vaccine and immunization). At present $42 \%$ of the National EPI Program expanses are paid by the government and the remainder is provided by the external donors14.

The EPI program operates through out the country in collaboration with numerous (20-25) NGOs. During the mid 1980s government sought co-operation from NGOs including BRAC, CARE (Corporation for American Relief Everywhere), Proshika, Rangpur Dinajpur Rural Services (RDRS), ICDDR'B Rotary International and many smaller NGOs. Shortage of government manpower to provide immunization services led to the GONGO collaboration in EPI. NGOs have strengthened the immunization program throughout the country through providing training for vaccinators, managers and communicators, providing immunization services in areas where government services can not easily reach, providing many of the communication materials and activities which have supported program expansion and mobilizing local talent and resources for the program. Three NGOs namely, BRAC, CARE and RDRS provided extensive support to the EPI, each taking responsibility for certain selected upazilas (sub-districts) ${ }^{15}$. Thus government provides vaccine, human resources, and infrastructure, logistic and cold-chain. Private for profit sector participation in the program was another uniqueness of EPI partnership. Private sector was not involved in service delivery but played an active role in awareness creation through using media resources, such as stickers, posters. 
Nutrition Program of Bangladesh also involves two large-scale programs in two phases. In the initial phase it was known as Bangladesh Integrated Nutrition Program (1995-2002) and the later and present phase is called the National Nutrition Program (2002-2010). In response to the high rates of low birth weight and malnutrition, government undertook a pilot nutrition intervention supported by the World Bank, the Bangladesh Integrated Nutrition Project (BINP) in 1995. It was the first large-scale multisectoral project on nutrition in Bangladesh, which was implemented through partnership with NGOs and the community. BINP ceased its activities in 2002 and the experiences gained from it are now being used for a much larger National Nutrition Program (NNP). NNP aims to reduce malnutrition among women, adolescent girls and children. NNP also has encouraged partnership with NGOs and the community as BINP did but the program outcome is not that satisfactory. Despite some positive changes, levels of malnutrition in Bangladesh still remain as one of the highest in the world as approximately, $46 \%$ of under-5 children are underweight 15 .

\section{Conclusion}

In conclusion; by virtue of partnership, the country has achieved near universal coverage in immunization. From this model of partnership lessons are as follows:

- Partnership with government relevant ministries, NGOS, private sector and the community is crucial to the success.

- Strong commitment at all levels of government can make a program successful.

- Smooth flow of resources is a prerequisite to the success of partnership.

- Active involvement of local government can play an effective role in community mobilization and in ensuring efficient service delivery.

- Training, strong supervision and monitoring by all the partners is a key to the success of partnership.

- Communication among the partners leading to a strong sense of ownership, mutual trust and respect are significant concerns for the success of partnership.

- Role of each partner was clearly laid out which prevented from raising any confusion.

\section{References}

1. Moszoro M, Gasiorowski P. 'Optimal capital structure of public- private partnerships' IMF working paper 1/ 2008. Papers.ssrn.com (2008.01.25). Retrieved on 2011.11.20

2. The Private Finance Initiative (PFI). www. willis.com/client_solutions/services/PPP, Retrieved on 2011-11-20

3. Public Private Partnerships in Europe. www.cmslegal.cn/1tubband.FileSystem/files/ Publication/ed219c67-c7b1-40c6-a54d-3494ef 81ebc8, Retrieved on 2011-11-20.

4. PFI projects hit fresh low as few deals closed. www.ft.com/cms/s/o/58156c2e-007b-11df-b50600144feabdeo.html, Retrieved on 2011-11-20

5. Allen and Overy. www.allenovery. com/pages/ default.aspx, Retrieved on 2011-11-20

6. European Commission Communication on PPP November 2009. www.eib.org/epec/resources/dla-european- PPPreport-2009.

7. Health Organization. World Access to Drugs and Finance, Geneva, 1991. p.1, www.who. int/medicines /mdg/MDG08chapterEmedsEn.

8. Economic Relations Division, Ministry of Finance, Government of the People's Republic of Bangladesh. A National Strategy for Economic Growth and Poverty Reduction. p.35.

9. Ministry of Health and Family Welfare, Health and Population Sector Program (HPSP), NICARE and The British Council. Public Private Partnership - A DFID Supported Component of HPSP.

10. World Health Organization. Health Reform and Drug Financing, p. iii,

11. Shepard, D.S. Rural Health Insurance and Essential Health Services, cited in Desmet M, Chowdhury AQ, Islam MK: The Potential for Social Mobilization in Bangladesh: the Organization and Functioning of two Health Insurance Schemes, paper presented in Health Insurance in Development Countries, Antwerp, Belgium, January, 1997.

12. The Health Economics Unit, Ministry of Health and Family Welfare and Data International Ltd. Bangladesh. Bangladesh National Health Accounts 1996/1997. p.25.

13. Talukdar, L.R. et.al. "The Near Miracle: How Immunization Services are Delivered" in Huq, M.ed, Near Miracle in Bangladesh, Dhaka, UPL.

14. Perry. H. Health for All in Bangladesh: Lessons in Primary Health Care for the Twenty First Century, UPL, Dhaka.

15. BDHS (Bangladesh Demographic and Health Survey). Preliminary Report, National Institute of Population Research and Training Dhaka, Bangladesh, Mitra Associates Dhaka, Bangladesh, MEASERES DHS, Macro International Caverton Maryland, USA. 